\title{
Effect of Balance Exercise using a Combination of Isotonics for Proprioceptive Neuromuscular Facilitation on Balance and Walking Ability in Patients with Hemiplegia Due to Stroke
}

\author{
Beomryong Kima ${ }^{\oplus}$, Taewoo Kang ${ }^{b}$ (다

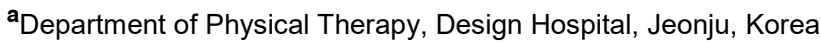 \\ ${ }^{b}$ Department of Physical Therapy, College of Health and Welfare, Woosuk University, Wanju, Korea
}

\begin{abstract}
Objective: This study aimed to determine the effect of proprioceptive neuromuscular facilitation (PNF) balance exercise on the ability to balance and walk in patients with hemiplegia caused by stroke.
\end{abstract}

Design: A randomized controlled trial

Methods: Following baseline measurements, patients $(n=24)$ with hemiplegia caused by stroke were randomized into two groups: the PNF balance group $(n=12)$ that received PNF balance exercise and the balance group $(n=12)$ that received general balance exercise. Each group joined the intervention for 30 minutes, 5 times per week for 6 weeks. Both groups performed the Timed Up and Go test (TUG) and Berg Balance Scale (BBS) for balance, as well as the 10-meter walking test (10MWT) and 6-minute walk test (6MWT) for walking. The data were collected both before and after the intervention. The paired t-test was used to compare the post-intervention changes compared with pre-intervention data. An independent t-test was used to analyze the differences in the dependent variables between the two groups.

Results: After the 6-week intervention, both groups showed significant improvements in balance (TUG, BBS) and walking (10MWT, 6MWT) parameters $(\mathrm{p}<0.05)$. The patients in the PNF balance group showed greater improvements in balance (TUG, BBS) and walking (10MWT, 6MWT) than those in the balance group $(\mathrm{p}<0.05)$.

Conclusions: PNF balance exercise shows improvements in balance and walking parameters in patients with hemiplegia caused by stroke.

Key Words: Balance exercise, Proprioceptive neuromuscular facilitation, Stroke, Walking ability

서론

뇌졸중 발생 이후 일반적인 특징은 운동능력의 감소이며, 이는 오른쪽과 왼쪽의 불균형을 발생시키고 비대칭적인 자세를 초래한다[1]. 운동능력의 감소에 따른 비대칭적인 자세는 신체 중심을 유지하는 능력을 감소시키고, 평형과 정위 반응에 영향을 미쳐 균형 및 심각한 자세 조절 능력 의 문제를 발생시키며, 보행과 일상생활동작수행에 장애 를 초래하게 된다[1]. 뇌졸중 환자들의 균형은 낙상 예방, 일상생활동작수행 및 독립적 생활을 위해 기본이 되는 운 동능력이다[2].
균형이란 중력의 변화에 적응하고 대항하여 바로 선 자세 를 유지하는 능력으로 정의되며, 신체의 정적과 동적인 움직임이 발생하는 동안 신체의 무게 중심이 지지면 안에서 위치하도록 하는 자세 조절 기전을 통하여 균형을 유지할 수 있게 된다[3]. 균형을 유지하기 위해서는 적절한 다리 근력이 필요하며[4], 다리 근육의 약화는 균형을 유지하는 데 부정적 영향을 미치는 중요한 요인으로 작용하여 낙상 의 위험성을 증가시키게 된다[5]. 신체의 움직임과 보행은 필수적인 요소로 충분한 다리 근력과 균형 및 자세 조절 이 필요하기 때문에, 다리 근력과 균형 및 자세 조절 능력 을 향상시키기 위한 물리치료적인 접근으로 다양한 중재

Received: Nov 23, 2021 Revised: Dec 24, 2021 Accepted: Dec 28, 2021

Corresponding author: Taewoo Kang (ORCID https://orcid.org/0000-0002-0083-2726)

443, Samnye-ro, Samye-eup, Wanju-gun Jeonbuk, 55338, Republic of Korea,

Department of Physical Therapy, College of Health and Welfare, Woosuk University

Tel: +82-63-290-1655 Fax: +82-63-290-1410 E-mail: ktwkd@hanmail.net

This is an Open-Access article distributed under the terms of the Creative Commons Attribution Non-Commercial License (http://creativecommons.org/licenses/ by-nc/4.0) which permits unrestricted non-commercial use, distribution, and reproduction in any medium, provided the original work is properly cited.

Copyright @ 2021 Korean Academy of Physical Therapy Rehabilitation Science 
방법들이 뇌졸중 환자들에게 적용되어 지고 있다. 몇 가지 물리치료적인 접근으로 점진적 과제지향적 다리근력강화 운동[6], 몸통 안정화 운동[7], 안정과 불안정 지지면에서의 균형 운동[8] 및 고유수용성신경근촉진법(proprioceptive neuromuscular facilitation, PNF)[9] 등의 많은 중재 방 법에 대한 연구가 지속적으로 이루어지고 있다.

이러한 중재 방법 중 PNF는 특징적으로 나선형과 대 각선 패턴을 사용함으로써 고유수용기를 자극하여 신경 근육반응을 촉진하여 3 차원적인 기능적 움직임을 증진시 키는 방법으로 운동 단위가 최대로 동원되도록 함으로써 근력과 균형 능력의 향상을 위한 효과적인 기법으로 알려 져 있다[10]. 또한, $\mathrm{PNF}$ 의 치료적 기법 중 등장성혼합기 법은 움직임을 일으키는 근육 그룹에 이완 없이 지속적으 로 구심성, 편심성 및 안정성 수축을 이끌어나가는 기법 으로 능동적인 움직임 조절, 협응력, 가동범위 증가, 근력 강화 및 움직임의 편심성 조절을 위한 기능적 훈련을 위 하여 사용되고 있다[11]. PNF의 등장성혼합기법을 적용 한 연구들을 살펴보면, $\mathrm{Kang}$ 과 $\mathrm{Kim}[8]$ 은 편측무시가 있 는 뇌졸중 환자를 대상으로 PNF 내려치기 패턴과 함께 등장성혼합기법을 적용하여 편측무시와 균형 능력 및 일 상생활수행에 향상을 보고하였고, 목 통증 환자에게 아래 등세모근 강화를 목적으로 등장성혼합기법을 적용한 결 과 목 움직임 향상과 목 통증 및 장애 수준의 감소를 보 고하였으며[12], $\mathrm{PNF}$ 의 등장성혼합기법을 65세이상 노 인들을 대상으로 적용한 결과 균형 능력에 개선을 보고하 였다[13]. 선행연구들을 살펴본 결과, $\mathrm{PNF}$ 의 등장성혼합 기법을 적용한 집단과 일반적인 물리치료를 적용한 집단 으로 배정하여 움직임 향상이나 균형 능력 개선에 효과적 이라는 연구결과들이 제시되고있지만[8,12], 선행연구들 에서 등장성혼합기법의 순수한 효과를 알아본 연구는 부 족한 실정이다.
따라서, 본 연구에서는 뇌졸중 환자를 대상으로 동일한 균형 운동프로그램에 $\mathrm{PNF}$ 의 등장성혼합기법을 적용한 $\mathrm{PNF}$ 균형 운동군과 아무런 기법 적용없이 순수한 균형 운동만 적용한 균형 운동군으로 배정하여 균형 및 보행 능력에 미치는 효과를 알아보고자 하였다.

\section{연구 방법}

연구 대상

연구 대상자는 전라북도 전주시 소재한 $\mathrm{D}$ 병원에서 뇌 졸중으로 인한 편 마비를 진단받고, 입원하여 신경계물리 치료를 받고 있는 24 명을 대상으로 하였으며, 다음의 선 별 기준을 거쳐 선별하였다.

대상자의 선정 기준은 균형에 영향을 미칠 수 있는 전 정기관이나 시각에 이상이 없는 자, 관절 움직임 범위에 제한과 같은 정형 외과적 질환이 없는 자, 연구자의 지시 내용을 이해하고 따를 수 있는 한국형 간이 정신상태 검사 (mini-mental state examination-Korean version, MMSE-K) 의 결과, 점수가 24점 이상으로 훈련을 받기에 적합한 자 로 설정하였다[14]. 대상자의 제외 기준으로는 인지 능력 에 문제가 있는 자, 편측무시 증후군이 있는 자, 연구에 잠재적인 방해 요인이 될 정도의 근골격계의 이상소견을 가진 자로 설정하였다.

대상자 모집공고를 통해서 30 명의 대상자가 모집 되었 으며, 이중 포함 기준을 충족하지 못한 5 명과 참여 거부 를 요청한 1 명 총 6 명이 탈락되어 24 명의 대상자가 연구 에 참여하였다. 이들을 각각 $\mathrm{PNF}$ 균형 운동군 12 명과 균 형 운동군 12 명으로 무작위 배정하여 진행하였다. 무작위 배정은 무작위 배치프로그램(GraphPad Prism software, GraphPad Software Inc., USA)을 사용하여 진행되었다 (Table 1)(Figure 1).

Table 1. General characteristics of the participants

$(n=24)$

\begin{tabular}{lllll}
\hline & PNF balance group $(\mathbf{n = 1 2})$ & $\begin{array}{l}\text { Balance group }(\mathbf{n}=\mathbf{1 2}) \\
\text { Mean } \pm \text { SD }\end{array}$ & $\chi^{2} / \mathbf{t}$ & p \\
\hline Genaracteristics & Mean \pm SD & $8 / 4$ & 0.000 & 1.000 \\
Age (years) & $8 / 4$ & $61.25 \pm 2.80$ & 0.000 & 1.000 \\
Height (cm) & $61.25 \pm 2.60$ & $164.33 \pm 8.33$ & 0.485 & 0.632 \\
Body weight (kg) & $165.92 \pm 7.65$ & $68.42 \pm 7.32$ & -0.328 & 0.746 \\
Hemiplegia side (right/left) & $67.42 \pm 7.63$ & $7 / 5$ & 0.178 & 0.673 \\
Stroke type (infarction/hemorrhage) & $9 / 3$ & $10 / 2$ & 0.253 & 0.615 \\
Stroke onset (months) & $20.08 \pm 4.25$ & $20.08 \pm 3.23$ & 0.000 & 1.000 \\
MMSE-K (scores) & $27.08 \pm 1.73$ & $27.33 \pm 2.31$ & -0.300 & 0.767 \\
\hline
\end{tabular}

SD: standard deviation, PNF: proprioceptive neuromuscular facilitation, MMSE-K: mini mental status examination-Korean version. 


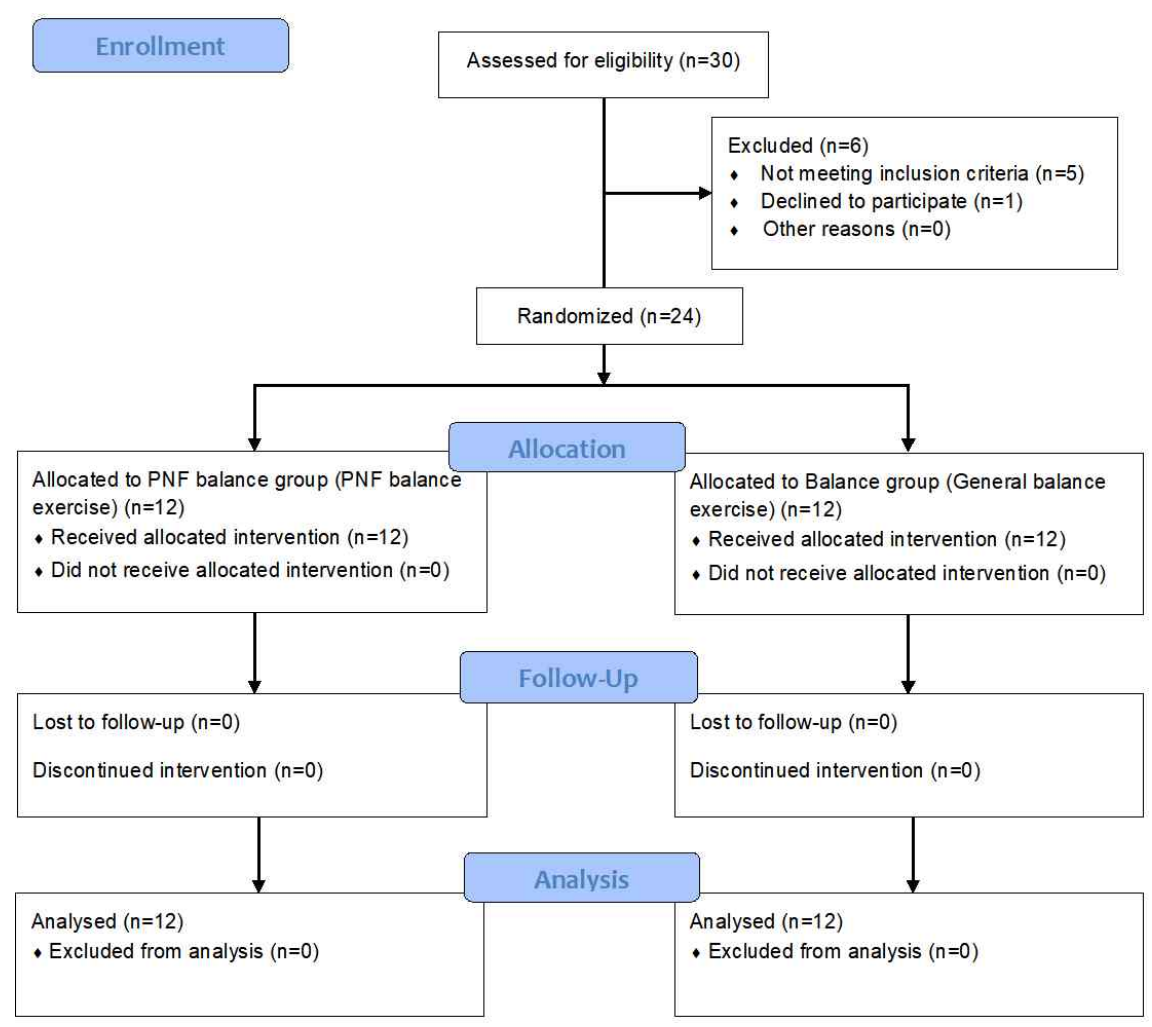

Figure 1. Study flow diagram

\section{실험 방법}

$\mathrm{PNF}$ 균형 운동군과 균형 운동군은 $\mathrm{Ji}$ 등[15]이 제시한 거울을 이용한 시각적 되먹임 운동 프로그램을 수정하여 적용하였다. 두 군은 주 5 회 6 주간 30 분의 운동 프로그램 에 참여하였으며, 환자가 지치거나 훈련을 제대로 이행하 기 어려울 경우, 중간에 적당한 휴식을 취하도록 하였다. 동작은 최대한 천천히 하도록 하여 근육의 동원을 최대한 할 수 있도록 하였다.

\section{PNF 균형 운동군}

PNF 균형 운동군은 Figure 2와 같은 동작을 치료사에 의해 PNF의 등장성혼합기법과 함께 시행되었다. $\mathrm{PNF}$ 의 등장성혼합기법은 강화하고자하는 근육군을 이완없이 동 작에 대해 구심성, 원심성 및 안정성 수축을 결합하여 적 용하는 방법으로 근력 강화, 협응 작용, 능동적 범위 조절 등을 목적으로 사용되며, 본 연구에서는 다리 근력 강화 를 통해 균형과 보행 능력의 향상을 목적으로 시행하였다. $\mathrm{PNF}$ 균형 운동군의 운동 동작은 5 동작이며, 다음과 같이 시행되었다. (1) 양쪽 다리를 어깨넓이만큼 벌리고 서기 자세에서 양쪽의 무릎을 약 20 도 굽힘하였다가 폄하는 동 작을 등장성혼합기법을 적용하여 20회 시행한다. (2) 마 비측 다리로 체중의 $50 \%$ 이상을 이동하여 유지하는 동작
을 등장성혼합기법을 적용하여 20회 시행한다. (3) 비마 비측 엉덩이와 다리를 높이를 조절할 수 있는 테이블 위 에 올린 상태에서 마비측 엉덩관절과 무릎관절을 약 20 도 굽힘 위치로 놓고 완전히 폄한 상태로 만드는 동작을 등 장성혼합기법을 적용하여 20회 시행한다. (4) 의자에서 천천히 앉기 직전까지 갔다가 일어나는 동작을 등장성혼 합기법을 적용하여 20회 시행한다. (5) 마비측 다리를 1 발자국 앞으로 이동한 후 마비측 다리로 체중을 부하하면 서 같은쪽 무릎을 굽힘하였다가 폄하는 동작을 등장성혼 합기법을 적용하여 20 회 시행한다.

\section{균형 운동군}

균형 운동군은 Figure 3 과 같은 동작을 $\mathrm{PNF}$ 의 등장성 혼합기법 적용없이 치료사의 감독하에 시행되었다. 균형 운동군의 운동 동작은 5 동작이며, 다음과 같이 시행되었 다. (1) 양쪽 다리를 어깨넓이만큼 벌리고 선 상태에서 양 쪽 무릎을 약 20 도 굽힘하였다가 폄하는 동작을 치료사의 감독하에 적용하여 20회 시행한다. (2) 마비측 다리로 체 중의 $50 \%$ 이상을 이동하여 유지하는 동작을 치료사의 감 독하에 적용하여 20회 시행한다. (3) 비마비측 엉덩이와 다리를 높이를 조절할 수 있는 테이블 위에 올린 상태에 서 마비측 엉덩관절과 무릎관절을 약 20 도 굽힘 위치에 놓고 완전히 신전한 상태로 펴는 동작을 치료사의 감독하 


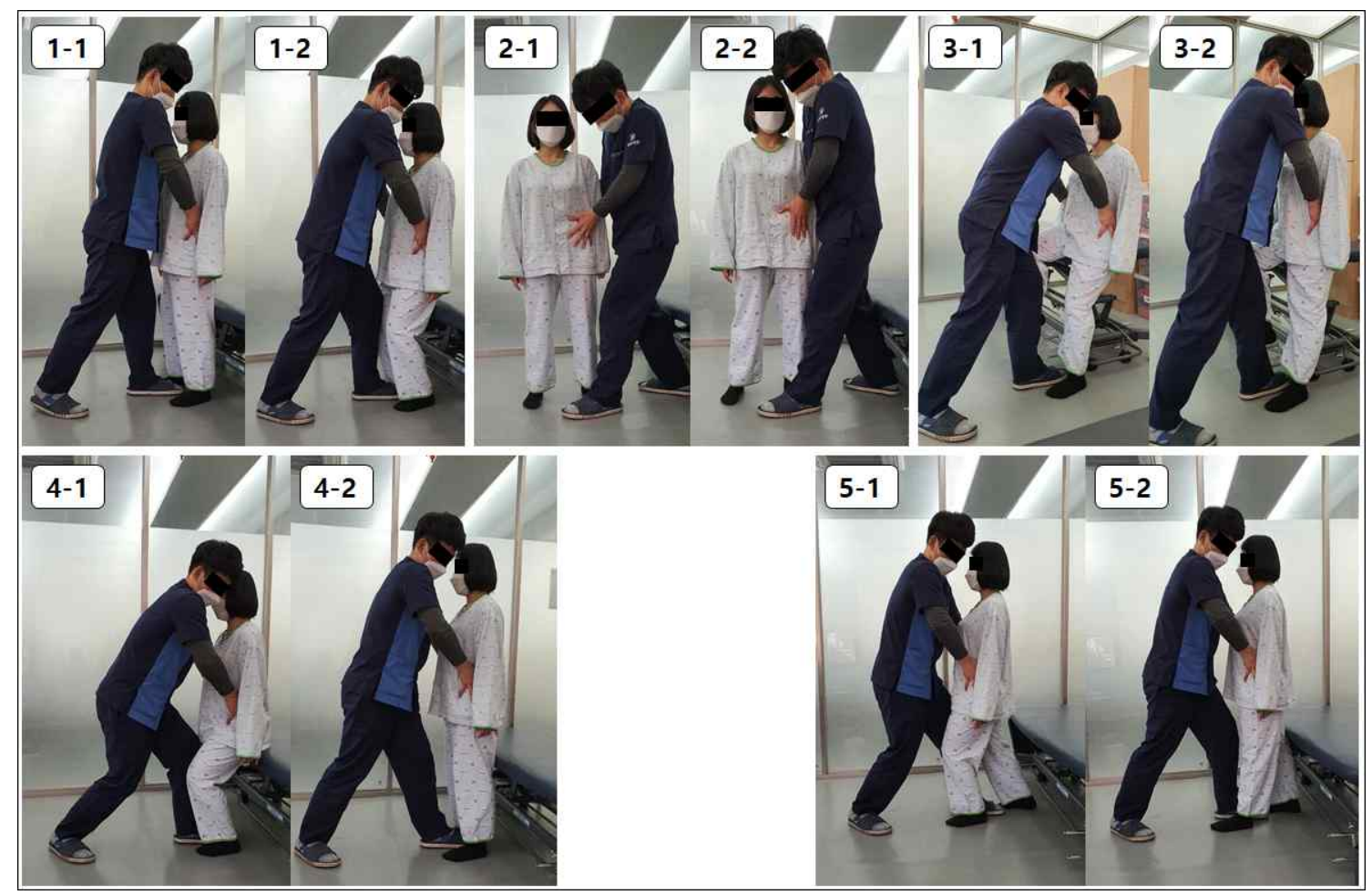

Figure 2. PNF balance exercise

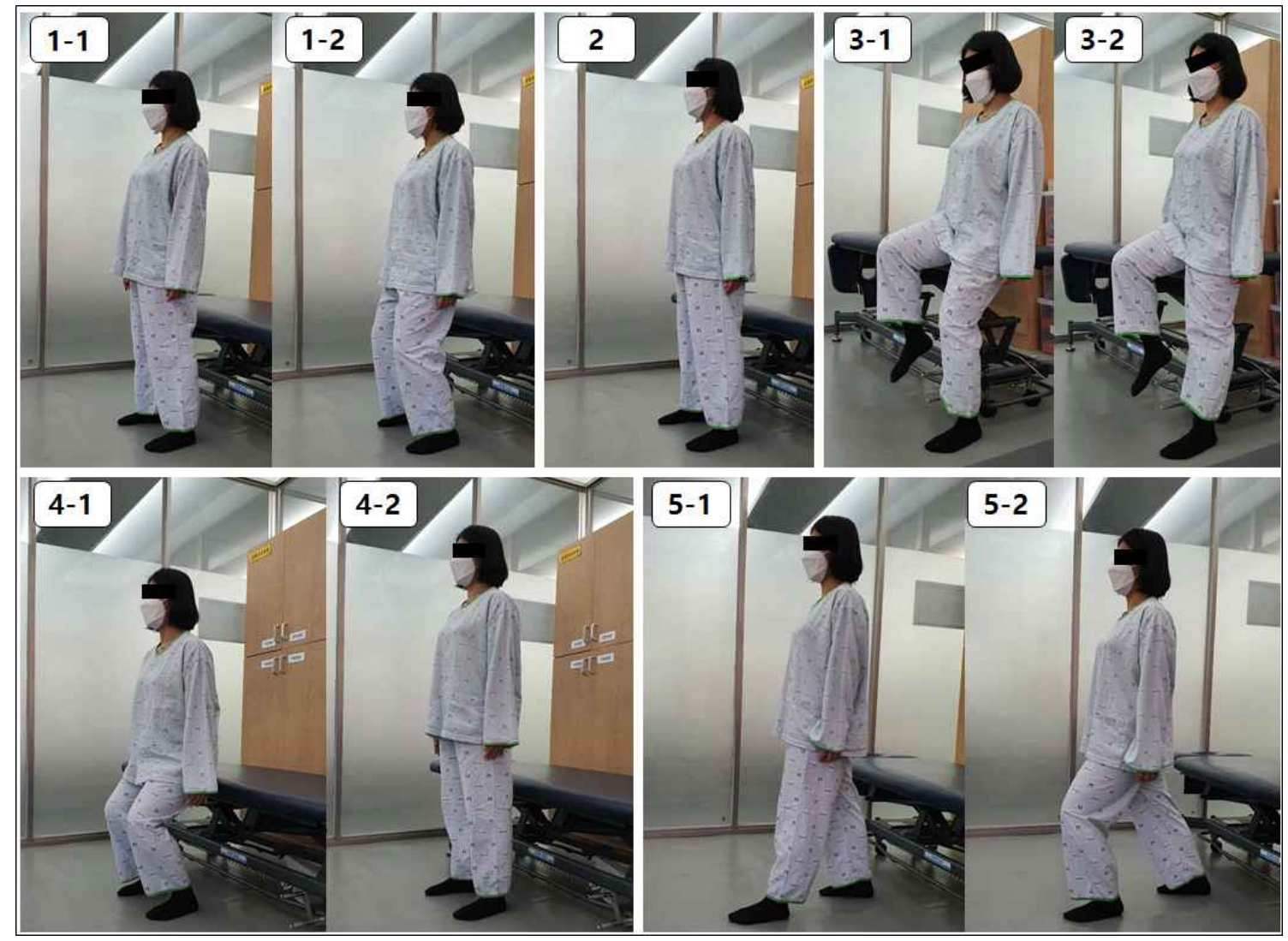

Figure 3. General balance exercise 
에 적용하여 20회 시행한다. (4) 의자에서 천천히 앉았다 가 일어나는 동작을 치료사의 감독하에 적용하여 20회 시 행한다. (5) 마비측 다리를 1 발자국 앞으로 이동한 후 마 비측 다리로 체중을 실으면서 같은쪽 무릎을 구부렸다가 펴는 동작을 치료사의 감독하에 적용하여 20 회 시행한다.

\section{측정 도구}

\section{의자에서 일어나 걷기 검사}

균형을 측정하기 위해 의자에서 일어나 걷기 검사 (timed up and go test, TUG)를 활용하였다. TUG는 기 본적인 운동능력과 균형능력을 빠르게 측정할 수 있는 검 사 도구로 팔걸이가 있는 높이 $50 \mathrm{~cm}$ 의 의자에서 일어나 앞에 $3 \mathrm{~m}$ 떨어진 지점을 돌아 다시 의자에 앉는데 까지 소요된 시간을 측정하는 방법이다. 1 회 연습 후 3 회 반복 측정하여 평균값을 제시하였다[16]. $\mathrm{TUG}$ 는 검사자 내, 간 신뢰도 $r=0.98 \sim 0.99$ 의 높은 신뢰도를 보이는 도구이 다[17].

\section{버그 균형 척도}

균형의 기능적 수행능력 정도를 측정하기 위해 버그 균 형 척도(Berg balance scale, BBS)를 활용하였다. BBS는 $\operatorname{Berg}$ 등 [18]에 의해서 개발된 것으로서 일상생활동작수 행에서 일반적으로 수행되는 14 개 항목의 기능적인 과제 들로 구성되어있다. $\mathrm{BBS}$ 는 앉기, 서기 및 자세 변화 3 개 의 영역을 최고 4 점에서 최소 0 점을 적용하여 총 56 점을 만점으로 측정된다. $\mathrm{BBS}$ 는 검사자 내, 간 신뢰도 $\mathrm{r}=0.98$ $\sim 0.99$ 의 높은 신뢰도를 보이는 도구이다[19].

\section{0 미터 보행 검사}

10 미터 보행 검사(10-meter walking test, 10MWT)는 보행 능력 중 보행 속도를 평가하기 위한 검사 도구로 가 속과 저속의 효과를 피하기 위하여 측정하는 10 미터거리 전과 후로 2 미터거리를 두었고, 초 시계로 10 미터 거리에 대 한 소요시간을 측정하였다. 1 회 연습을 한 후 3 회 반복 측정 하여 평균값을 제시하였다. $10 \mathrm{MWT}$ 는 검사자 내, 간 신뢰 도 $\mathrm{r}=0.88 \sim 0.99$ 의 높은 신뢰도를 보이는 도구이다[20].

\section{6분 보행 검사}

6분 보행 검사(6-minute walk test, 6MWT)는 일반적 으로 보행지구력을 측정하는 검사방법 중하나이다[21]. $6 \mathrm{MWT}$ 는 평편한 바닥에 $20 \mathrm{~m}$ 거리를 지정하고 출발 지 점과 반환 지점을 표시하여 6 분 동안 최대한 $20 \mathrm{~m}$ 거리를
반복해서 걷도록 하여 출발 지점과 반환 지점간의 반복 횟수를 포함한 6 분 동안의 보행 거리를 미터 $(\mathrm{m})$ 단위로 측정하는 방법이다. $6 \mathrm{MWT}$ 는 검사자 내 신뢰도는 $\mathrm{r}=$ 0.91 로 높은 신뢰도를 보이는 도구이다[22].

\section{자료 처리}

본 연구를 위한 자료분석은 윈도우용 통계프로그램인 SPSS/PC Statistics 23.0 software(SPSS Inc, USA)을 활 용하였다. Shapiro-wilk로 대상자의 일반적인 특징은 정 규성 검정을 하였으며, 빈도차이 검정을 위하여 카이제곱 검정(chi-squared test) 및 평균차이 검정을 위하여 독립표 본 t-검정(independent t-test)로 통계처리 하였다. PNF 균 형 운동 전과 후 집단 내 균형 및 보행 능력의 변화를 비 교하기 위하여 대응표본 t-검정(paired t-test)으로 통계처 리 하였으며, PNF 균형 운동과 균형 운동의 집단 간의 차이를 비교하기 위해 독립표본 $\mathrm{t}$-검정으로 통계처리 하였 다. 모든 통계학적 유의수준은 $\alpha=0.05$ 로 설정하였다.

\section{연구 결과}

\section{의자에서 일어나 걷기 검사의 변화 비교}

집단 내 의자에서 일어나 걷기 검사의 변화는 PNF 균 형 운동군에서 유의하게 감소하였고 $(\mathrm{p}<0.05)$, 균형 운동 군에서도 유의하게 감소하였다 $(\mathrm{p}<0.05)$. 중재 전과 후 변 화량에 따른 집단 간 의자에서 일어나 걷기 검사의 비교 에서는 PNF 균형 운동군과 균형 운동군 사이에서 유의한 차이가 있었다 $(\mathrm{p}<0.05)($ Table 2$)$.

\section{버그 균형 척도의 변화 비교}

집단 내 버그 균형 척도의 변화는 PNF 균형 운동군에 서 유의하게 감소하였고 $(\mathrm{p}<0.05)$, 균형 운동군에서도 유 의하게 감소하였다 $(\mathrm{p}<0.05)$. 중재 전과 후 변화량에 따른 집단 간 버그 균형 척도의 비교에서는 $\mathrm{PNF}$ 균형 운동군 과 균형 운동군 사이에서 유의한 차이가 있었다 $(\mathrm{p}<0.05)$ (Table 3).

\section{0 미터 보행 검사의 변화 비교}

집단 내 10 미터 보행 검사의 변화는 PNF 균형 운동군 에서 유의하게 감소하였고 $(\mathrm{p}<0.05)$, 균형 운동군에서도 유의하게 감소하였다 $(\mathrm{p}<0.05)$. 중재 전과 후 변화량에 따른 집단 간 10 미터 보행 검사의 비교에서는 PNF 균형 운동 군과 균형 운동군 사이에서 유의한 차이가 있었다 $(\mathrm{p}<0.05)$ (Table 4). 
Table 2. TUG at baseline and post intervention

$(\mathrm{n}=24)$

\begin{tabular}{llll}
\hline & $\begin{array}{l}\text { PNF balance group }(\mathbf{n}=\mathbf{1 2}) \\
\text { Mean } \pm \text { SD }\end{array}$ & $\begin{array}{l}\text { Balance group }(\mathbf{n}=\mathbf{1 2}) \\
\text { Mean } \pm \text { SD }\end{array}$ & $\mathbf{t}(\mathbf{p})$ \\
\hline TUG (baseline) & $16.43 \pm 1.15$ & $16.11 \pm 2.55$ & $0.390(0.700)$ \\
TUG (post-intervention) & $12.60 \pm 1.33$ & $14.40 \pm 2.42$ & $6.255\left(0.000^{\mathrm{b}}\right)$ \\
Decrease in TUG time & $3.83 \pm 0.84$ & $1.71 \pm 0.82$ & \\
$\mathrm{t}(\mathrm{p})$ & $15.821\left(0.000^{\mathrm{a}}\right)$ & $7.203\left(0.000^{\mathrm{a}}\right)$ & \\
\hline
\end{tabular}

${ }^{\text {a }}$ Significant difference within groups $(\mathrm{p}<0.05)$, ${ }^{\mathrm{b}}$ Significant difference between groups $(\mathrm{p}<0.05)$.

SD: standard deviation, PNF: proprioceptive neuromuscular facilitation, TUG: timed up and go test.

Table 3. BBS at baseline and post intervention

$(\mathrm{n}=24)$

\begin{tabular}{llll}
\hline & PNF balance group $(\mathbf{n}=\mathbf{1 2})$ & Balance group $(\mathbf{n}=\mathbf{1 2})$ & t $(\mathbf{p})$ \\
\hline Mean \pm SD & $38.00 \pm 3.72$ & $38.00 \pm 3.57$ & $0.000(1.000)$ \\
BBS (post-intervention) & $47.83 \pm 3.46$ & $43.50 \pm 3.87$ & $-9.299\left(0.000^{\mathrm{b}}\right)$ \\
Changes in BBS & $-9.83 \pm 1.47$ & $-5.50 \pm 0.67$ & \\
$\mathrm{t}(\mathrm{p})$ & $-23.223\left(0.000^{\mathrm{a}}\right)$ & $-28.260\left(0.000^{\mathrm{a}}\right)$ & \\
\hline
\end{tabular}

${ }^{\mathrm{a}}$ Significant difference within groups $(\mathrm{p}<0.05)$, ${ }^{\mathrm{b}}$ Significant difference between groups $(\mathrm{p}<0.05)$.

SD: standard deviation, PNF: proprioceptive neuromuscular facilitation, BBS: Berg balance scale.

Table 4. 10MWT at baseline and post intervention

$(n=24)$

\begin{tabular}{llll}
\hline & $\begin{array}{l}\text { PNF balance group }(\mathbf{n}=12) \\
\text { Mean } \pm \text { SD }\end{array}$ & $\begin{array}{l}\text { Balance group }(\mathbf{n = 1 2}) \\
\text { Mean } \pm \text { SD }\end{array}$ & t (p) \\
\hline 10MWT (baseline) & $15.91 \pm 2.32$ & $16.07 \pm 2.00$ & $0.187(0.854)$ \\
10MWT (post-intervention) & $11.98 \pm 1.49$ & $13.68 \pm 2.20$ & $2.222\left(0.037^{\mathrm{b}}\right)$ \\
Decrease in 10MWT time & $3.93 \pm 2.09$ & $2.39 \pm 1.16$ & \\
$\mathrm{t}(\mathrm{p})$ & $6.496\left(0.000^{\mathrm{a}}\right)$ & $7.129\left(0.000^{\mathrm{a}}\right)$ & \\
\hline
\end{tabular}

${ }^{\mathrm{a}}$ Significant difference within groups $(\mathrm{p}<0.05)$, ${ }^{\mathrm{b}}$ Significant difference between groups $(\mathrm{p}<0.05)$.

SD: standard deviation, PNF: proprioceptive neuromuscular facilitation, 10MWT: 10 meter walking test.

6분 보행 검사의 변화 비교

집단 내 6분 보행 검사의 변화는 PNF 균형 운동군에 서 유의하게 감소하였고 $(\mathrm{p}<0.05)$, 균형 운동군에서도 유
의하게 감소하였다 $(\mathrm{p}<0.05)$. 중재 전과 후 변화량에 따른 집단 간 6분 보행 검사의 비교에서는 PNF 균형 운동군과 균형 운동군 사이에서 유의한 차이가 있었다 $(\mathrm{p}<0.05)$ (Table 5).

Table 5. 6MWT at baseline and post intervention

$(\mathrm{n}=24)$

\begin{tabular}{llll}
\hline & PNF balance group $(\mathbf{n}=\mathbf{1 2})$ & Balance group $(\mathbf{n}=\mathbf{1 2})$ & t $(\mathbf{p})$ \\
\hline Mean \pm SD & Mean \pm SD & $0.160(0.874)$ \\
6MWT (baseline) & $314.67 \pm 38.97$ & $312.00 \pm 42.54$ & $-4.830(0.000 \mathrm{~b})$ \\
Increase in 6MWT & $358.08 \pm 31.14$ & $328.92 \pm 38.96$ & $-16.92 \pm 7.51$ \\
$\mathrm{t}(\mathrm{p})$ & $-43.42 \pm 17.46$ & $-7.800(0.000 \mathrm{a})$ & \\
\hline
\end{tabular}

${ }^{\mathrm{a}}$ Significant difference within groups $(\mathrm{p}<0.05)$, ${ }^{\mathrm{b}}$ Significant difference between groups $(\mathrm{p}<0.05)$.

SD: standard deviation, PNF: proprioceptive neuromuscular facilitation, 6MWT: 6 minute walk test. 


\section{고찰}

균형과 보행 능력의 감소는 신경계 환자에게 빈번하게 발생하는 낙상이나 비정상적인 보행 패턴을 쉽게 일으키 며, 독립적인 생활이 어렵게 되어 삶의 질을 매우 저하시 키는 것으로 보고되고 있다[23]. 따라서 본 연구는 뇌졸중 환자의 기능적 움직임을 회복시키기 위한 효과적인 운동 방법을 알아보고자 시행되었다.

본 연구에 활용된 PNF치료 컨셉은 신경계 및 근골격 계 환자에게 근력향상 및 운동조절능력의 증진, 몸통 안 정성 향상을 통한 균형능력 증진을 목표로 널리 사용되는 중재방법 중 하나이다[6][7]. 본 연구에서 환자에게 적용 된 등장성혼합기법은 3 가지의 근수축형태인 구심성, 원심 성 및 안정성 수축을 동작을 할 때, 가장 많은 힘을 발휘 하는 근육에 대해 이완 없이 움직임을 유발시키는 기법이 다[11]. 등장성혼합기법의 효과는 근육의 근력 강화, 능동 조절 능력 향상, 협응력 향상, 관절의 가동범위 증가뿐만 아니라 일상생활의 기능적 훈련에 효과적이다[11]. 이러 한 $\mathrm{PNF}$ 의 등장성혼합기법의 효과 때문에 $\mathrm{PNF}$ 의 등장성 혼합기법을 적용한 PNF 균형 운동군이 아무런 기법 적용 없이 순수한 균형 운동만 적용한 균형 운동군보다 균형 및 보행 능력에 향상을 보인 것으로 사료되며, PNF의 등 장성혼합기법을 다양한 운동프로그램과 접목하여 수행한 다면 더욱 효과적인 운동효과를 얻을 것으로 생각된다.

본 연구의 결과 PNF 균형 운동군과 균형 운동군 모두 운동 전보다 후에 균형 능력(TUG, BBS)이 유의하게 증 가하였고, $\mathrm{PNF}$ 균형 운동군이 균형 운동군 보다 균형 능 력에 더욱 효과적인 향상을 보고하였다. Choi와 $\mathrm{Seo[24]}$ 는 뇌졸중 환자 42명을 대상으로 $\mathrm{PNF}$ 을 이용한 운동이 균형 능력에 미치는 영향을 알아보고자 PNF 스케이터 패 턴을 적용한 실험군과 일반적 운동치료를 적용한 대조군 으로 배정하여 6 주 동안 운동을 실시하였다. 그 결과 $\mathrm{PNF}$ 스케이터 패턴을 적용한 실험군이 대조군보다 균형 능력에서 더 긍정적인 영향을 보고하였고, Cho 등[25]은 뇌졸중 환자 30 명을 대상으로 $\mathrm{PNF}$ 을 적용한 상하지 협응 운동을 적용하여 균형 능력에 향상을 보고하였으며, Lim [26]은 뇌졸중을 겪고있는 환자 22명을 대상으로 스케이 터와 스프린터를 활용한 PNF 패턴 운동을 적용한 실험군 과 매트와 보행 운동 및 기능적 전기자극을 적용한 대조 군으로 무작위 배정하여 운동한 결과 실험군에서 균형 능 력에 향상을 보고하였다. 이러한 결과는 $\mathrm{PNF}$ 를 활용한 스케이터, 스프린터 및 상하지 협응 운동은 팔과 다리를 교대적으로 움직임으로써 협응력과 운동 조절력이 증가되 고, 수행과정에서 동작이 반복되면서 팔과 다리의 가동범 위 및 근력이 증가됨으로써 대상자들의 고유수용성감각을 회복시키고 마비측 다리 근력의 증가로 신체의 자세 조절
능력이 대칭적으로 향상되었기 때문에 균형 능력의 향상 을 가져온 것으로 사료된다.

Park 등[27]은 만성 뇌졸중 환자 30 명을 대상으로 균형 과 보행 능력 향상을 목적으로 PNF 허리 안정화 운동과 일반적 운동을 각각 적용한 결과 $\mathrm{PNF}$ 허리 안정화 운동군 이 일반적 운동군보다 균형 능력뿐만 아니라 보행 능력에 향상을 보고하였고, Kim과 Choi[23]은 기저핵 뇌졸중 환 자를 대상으로 PNF을 사용한 몸통 안정화 및 강화 운동을 통해 보행 능력에 향상을 보고하였으며, Jeong 등[28]은 $\mathrm{PNF}$ 팔다리결합패턴이 뇌졸중 환자의 마비측 다리 근육 활성도와 보행 능력에 어떠한 영향을 미치는 지를 알아보 고자 뇌졸중 환자 20명을 대상으로 하여 $\mathrm{PNF}$ 팔다리결합 패턴을 적용하는 실험군과 일반 운동치료만을 적용하는 대 조군으로 무작위 배정하여 6주간 운동하였다. 그 결과 $\mathrm{PNF}$ 팔다리결합패턴은 뇌졸중 환자의 마비측 근육 활성 도를 증가시키게 하며, 보행 능력 향상에 유용한 중재방법 으로 사용될 수 있음을 증명하였다. 본 연구에서도 PNF을 활용한 균형 운동군과 일반적인 균형 운동군 모두에서 운 동 전보다 후에 보행 능력(10MWT, 6MWT)의 유의한 향 상을 보였으며, 집단 간 비교에서도 균형 운동군에 비해 PNF 균형 운동군에서 유의한 보행 능력의 향상을 보였다. 이러한 선행 연구와 본 연구의 결과는 PNF기법의 적용은 일반 균형 운동과는 달리 치료사의 적절한 도수 접촉과 저 항에 의해 근육들의 수축을 증가시키고, 동작에 정확한 움 직임을 유도하기 때문에 보다 넓고 많은 부위를 간접적으 로 활성화 시켰을 것으로 생각되며, 일반적인 운동에 비해 PNF을 활용한 운동은 매우 능동적인 움직임을 많이 유발 하여 보행 능력에 향상을 보인 것으로 사료된다.

이러한 결과를 종합하면 고유수용성신경근촉진법의 등 장성혼합기법을 이용한 균형 운동이 자세 조절 능력의 향 상뿐만 아니라 더욱 효과적인 다리 근력의 향상을 통해 신체의 재정렬 확립과 균형 및 보행 능력에 긍정적인 영 향을 미쳤다고 생각된다. 본 연구의 제한점은 대상자의 수가 적어 모든 뇌졸중으로 인한 편마비 환자에 대하여 일반화시켜 해석하는데 어려움이 있고, 추적 관찰을 통해 사후 평가가 이루어지지 않았으며, 환자에게 주어진 운동 방법이 단순 했다는 점이다. 앞으로 다양한 환자에 대한 연구와 다양한 운동 방법의 수행을 통해 임상에서 뇌졸중 으로 인한 편 마비 환자에게 고유수용성신경근촉진법을 활용하여 다양한 효과를 가져올 수 있도록 좀 더 많은 연 구가 필요할 것으로 생각된다.

\section{결론}

본 연구의 목적은 뇌졸중 환자를 대상으로 $\mathrm{PNF}$ 균형 운동이 균형과 보행 능력 향상에 어떠한 영향을 주는지 
알아보고, $\mathrm{PNF}$ 균형 운동과 균형 운동의 효과를 비교해 보고자 하였다.

본 연구의 결과는 PNF 균형 운동이 균형 운동보다 균 형과 보행 능력 향상에 더 도움이 됨을 알 수 있었다. 따 라서, 뇌졸중 환자에게 균형과 보행 능력 향상을 위해 신 경계물리치료 임상현장에서 $\mathrm{PNF}$ 를 활용한 균형 운동이 활용될 수 있을 것이다.

\section{References}

1. Ikai T, Kamikubo T, Takehara I, et al. Dynamic postural control in patients with hemiparesis. Am J Phys Med Rehabil. 2003;82(6):463-469.

2. Ahn W. The training effect of balance pad in stroke. Korean Soc Sport Leisure Studies. 2008;32(1):803-811.

3. Shumway-Cook A, Woollacott MH. Motor control: translating research into clinical practice. Lippincott Williams \& Wilkins. 2007.

4. Kim DS, Choi IS, Kim SY. The impact of lower extremity strengthening exercise with step box and elastic band on balance ability and lower extremity muscular strength in community-living elderly individuals. J Korean Soc Phys Med. 2016;11(1):11-21.

5. Byun J, Lee K, Hwang B. An analysis of ankle range of motion, balance and leg muscle strength according to experienced falls in elderly people. Korean Soc Sport Leisure Studies. 2016;64(1): 909-916.

6. Kang TW, Kim HM, Kim BR. Effect of progressive resistance task-oriented strengthening exercise on balance and activities of daily living in stroke patients. PNF Mov. 2020;18(1):77-86.

7. Song MS, Kim BR, Kang TW. Effects of extra trunk exercise on balance, gait ability, and trunk control in patients with chronic stroke. J Spec Educ Rehabil. 2019;58(1):461-474.

8. Kang TW, Kim BR. Effect of proprioceptive neuromuscular facilitation chopping pattern on neglect, balance, and activity of daily living of stroke patients with hemi-spatial neglect: a randomized clinical trial. J Korean Soc Phys Med. 2019;14(2):107-115.

9. Kim BR, Kang TW. The effects of proprioceptive neuromuscular facilitation lower-leg taping and treadmill training on mobility in patients with stroke. Int J Rehabil Res. 2018;41(4):343-348.
10. Klein DA, Stone WJ, Phillips WT, et al. PNF training and physical function in assisted-living older adults. J Aging and Phys Act. 2002;10(4):476-488.

11. Adler SS, Beckers D, Buck M. PNF in practice: an illustrated guide. Springer. 2007.

12. Song MJ, Kang TW, Kim BR. The effect of lower trapezius strengthening exercise using PNF on pain, range of motion, and disability in patients with chronic neck pain. PNF Move. 2021;19(1):137-146.

13. Kang DW, Kang MK, Kang ES, et al. The effect of PNF technique application using thera-band on the balance and gait of females over 65 years old. J Korean Phys Ther Sci. 2011;18(1):1-10.

14. Song GB, Park EC. The effects of balance training on balance pad and sand on balance and gait ability in stroke patients. J Korean Soc Phys Med. 2016; 11(1):45-52.

15. Ji SG, PT, Nam GW, Kim MK, et al. The effect of visual feedback training using a mirror on the balance in hemiplegic patients. J Korean Soc Phys Med. 2011;6(2):153-163.

16. Suzuki K, Nakamura R, Yamada Y, et al. Determinants of maximum walking speed in hemiparetic stroke patients. Tohoku J Exp Med. 1990;162(4):337-344.

17. Podsiadlo D, Richardson S. (1991). The timed "Up \& Go": a test of basic functional mobility for frail elderly persons. J Am Geriatr Soc. 1991;39(2):142-148.

18. Berg K, Wood-Dauphine S, Williams J, et al. Measuring balance in the elderly: preliminary development of an instrument. Physiother Can. 1989; 41(6):304-311.

19. Berg K, Wood-Dauphinee S, Williams J. The Balance Scale: reliability assessment with elderly residents and patients with an acute stroke. Scand J Rehabil Med. 1995;27(1):27-36.

20. Dean CM, Richards CL, Malouin F. Task-related circuit training improves performance of locomotor tasks in chronic stroke: a randomized, controlled pilot trial. Arch Phys Med Rehabil. 2000;81(4):409-417.

21. Swisher AK, Goldfarb AH. Use of the six-minute walk/run test to predict peak oxygen consumption in older adults. Cardiopulmonary Phys Ther J. 1998; 9(3):3-5.

22. Mossberg KA. Reliability of a timed walk test in persons with acquired brain injury. Am J Phys Med Rehabil. 2003;82(5):385-390. 
23. Kim BR, Choi MH. Effect of trunk strengthening and stabilization exercise using proprioceptive neuromuscular facilitation on balance and walking ability in patients with basal ganglia stroke. Korean J Neuromuscul Rehabil. 2020;10(1):24-32.

24. Choi W, Seo T. The effects of PNF skater pattern on the balance in stroke patients. J Korea Entertainment Industr Assoc. 2015;9(2):289-298.

25. Cho HS, Cha HG, Shin HS. The effects of PNF upper-and lower-limb coordinated exercise on the balancing and walking-abilities in stroke patients. PNF Mov. 2017;15(1):27-33.

26. Lim CG. The effects of proprioceptive neuromuscular facilitation (PNF) pattern exercise using the sprinter and the skater on balance and gait function in the stroke patients. J Korean Phys Ther. 2014;26(4):249-256.

27. Park JM, Shin YI, Yang SH. The effect of lumbar stabilization exercise with proprioceptive neuromuscular facilitation technique to balance and gait in chronic stroke patients. J Korean Academy Orthopedic Manual Phys Ther. 2012;18(1):65-72.

28. Jeong WS, Park SK, Park JH, et al. Effect of PNF combination patterns on muscle activity of the lower extremities and gait ability in stroke patients. Journal Korea Contents Assoc. 2012;12(1):318-328. 